This is a self-archived version of an original article. This version may differ from the original in pagination and typographic details.

Author(s): Baltazar, Margarida; Saarikallio, Suvi

Title: Strategies and mechanisms in musical affect self-regulation : A new model

Year: 2019

Version: Accepted version (Final draft)

Copyright: (c) The Authors, 2017.

Rights: In Copyright

Rights url: http://rightsstatements.org/page//nC/1.0/?language=en

Please cite the original version:

Baltazar, M., \& Saarikallio, S. (2019). Strategies and mechanisms in musical affect self-regulation : A new model. Musicae Scientiae, 23(2), 177-195. https://doi.org/10.1177/1029864917715061 


\title{
Strategies and mechanisms in musical affect self-regulation: A new model
}

\author{
Margarida Baltazar \\ Suvi Saarikallio \\ University of Jyväskylä, \\ Department of Music, Art, and Culture Studies \\ Finland
}

Corresponding Author:

Margarida Baltazar,

Department of Music, Art, and Culture Studies, P. O. Box 35, FI-40014 University of Jyväskylä,

Finland.

Website: http:/ / users.jyu.fi/ anmamace

Email: margarida.baltazar@jyu.fi

Author accepted manuscript.

Final published version: https:// doi.org/10.1177/1029864917715061

Baltazar, M., \& Saarikallio S., Strategies and Mechanisms in Musical Affect Self-Regulation: A New Model, Musicae Scientiae (advance online publication). Copyright (C [2017] (Baltazar \& Saarikallio). Reprinted by permission of SAGE Publications. 


\begin{abstract}
This study aimed at investigating the associations between regulation strategies and musical mechanisms involved in musical affect self-regulation. A sample of 571 participants was collected and the data regarding the reported strategies and mechanisms were analysed using correspondence analysis (CA). Three bipolar dimensions - cognition, feelings, and body - were retained for interpretation, thus revealing six contrasting strategic uses of music: cognitive work, entertainment, affective work, distraction, revival, and focus on situation. Clear associations between strategies and mechanisms emerged from the CA, connecting cognitive, feelings-focused, and situational processing with individual-dependent mechanisms and repairing, pleasure, and body-focused strategies with feature-dependent mechanisms. The novel observations about these associations renew the conceptual understanding of musical affect selfregulation and lay foundations for a new model that integrates regulatory strategies and mechanisms as intrinsic and interrelated components of this behaviour.
\end{abstract}

\title{
Keywords
}

affect regulation, correspondence analysis, emotion regulation, mechanisms, mood regulation, music, self-regulation, strategies 
Music provides people with innumerous possibilities of regulating their affective states (e.g. Groarke \& Hogan, 2015; Thoma, Scholz, Ehlert, \& Nater, 2012). These states consist of emotions (Tahlier, Miron, \& Rauscher, 2013), moods (Saarikallio \& Erkkilä, 2007), energy levels and arousal (DeNora, 1999), and focus and motivation (Bishop, Karageorghis, \& Loizou, 2007). The key features of musical self-regulation - affect, cognition, and music - have been recognized to be closely connected (Krumhansl, 2002); yet, how people use music's proprieties to manage their affective states is still intriguing and fascinating. With this paper, we will approach this topic by tackling two of the main aspects underlying musical affect regulation: the strategies employed through music to attain affective goals and the musical mechanisms that support self-regulation.

\section{Terminology and definitions}

Affect has been used in the literature as an umbrella term to include all the evaluative (positive or negative) states (Juslin \& Sloboda, 2010). However, due to the fuzzy borders between cognition, motivation, and emotion - which can be seen as a continuum (Fleckenstein, 1991; Scherer \& Peper, 2001) - there is 
still no consensus on what to include under this umbrella. Baltazar and

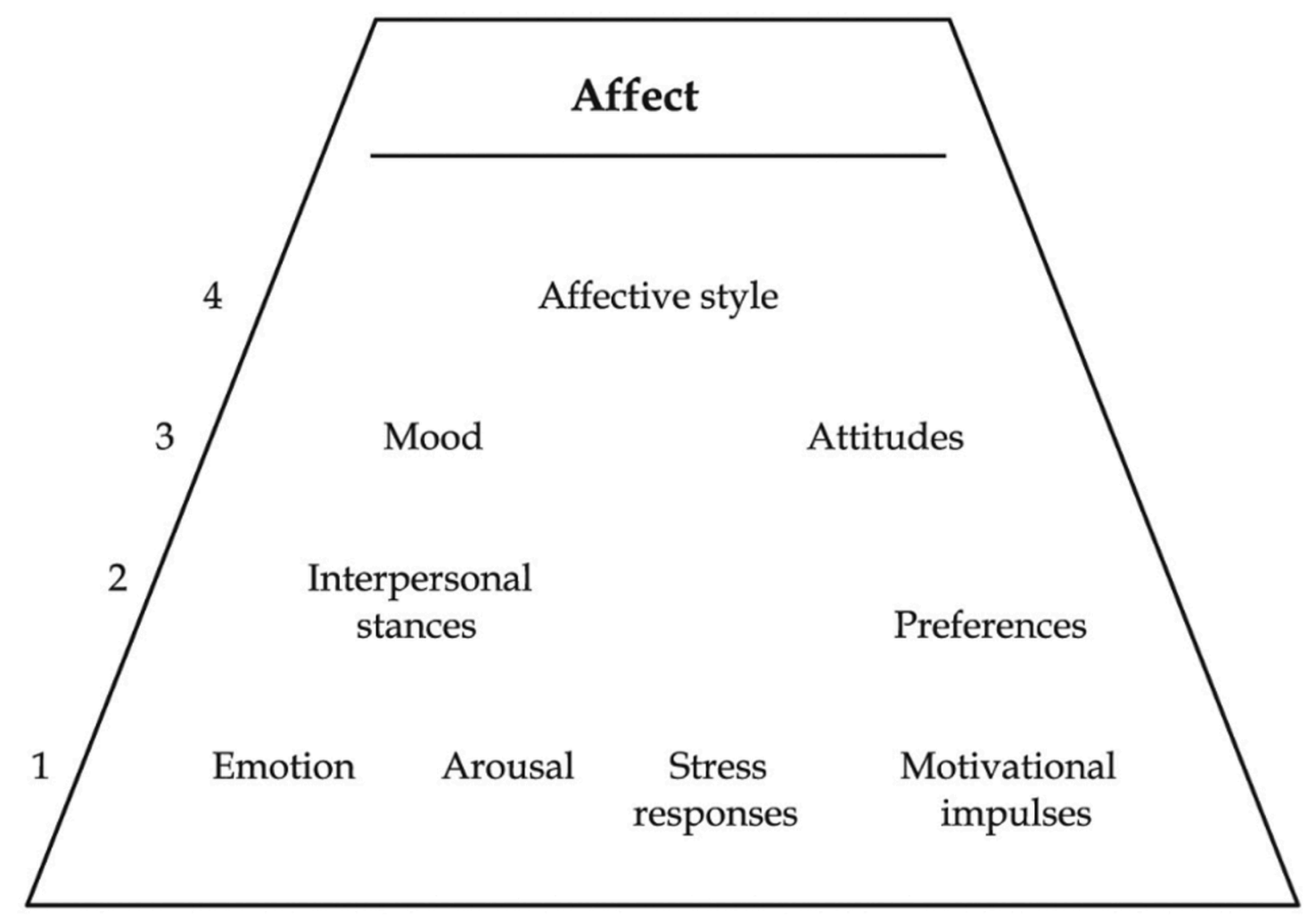

Figure 1. Affect as an umbrella term and the affective terms that are included in it, ranking from short duration (1) to long duration (4). From Baltazar \& Saarkikallio (2016). Reprinted by permission of Sage Publications.

Note. The duration ranking is based on Scherer (2000, 2004, 2005), and additional concepts were found in Ferguson, Hassin, \& Bargh (2008), Fleckenstein (1991), Gross \& Thompson (2007), Harmon-Jones \& Harmon-Jones (2015), Juslin \& Sloboda(2010), and Van Goethem (2010). The terms that are typically linked to cognitive phenomena refer to their affective component (e.g. motivation vs. motivational impulses). 
Saarikallio (2016) reviewed and compiled the affective phenomena that have been identified in the literature (Figure 1). In the present paper, a similar concept of affect is adopted. Affect regulation is defined, thus, as all attempts at creating, changing, or maintaining any of the affective states, positive or negative (e.g. emotion regulation, coping, mood regulation, arousal modulation; Gross, 2015; Gross \& Thompson, 2007).

Affect regulation is directed by a goal (conscious or unconscious) and the concrete approach people take to achieve the goal is a strategy (Koole, 2009, p. 10). Strategies take place in a certain context or activity (i.e. tactics; Van Goethem, 2010), which can, for instance, be listening to music, singing, or dancing. The underlying processes explaining why music then impacts emotions and allows affective regulation to occur are labelled mechanisms (Juslin \& Västfjäll, 2008b; Saarikallio, Baltazar, \& Västfjäll, 2017; Van Goethem \& Sloboda, 2011). For example, the strategy reappraisal (finding different interpretations for the situation) can be used while listening to music with empowering lyrics. The lyrics, in turn, are the mechanism facilitating affect regulation. Although some mechanisms are music-specific (e.g. rhythm), some mechanisms are general psychological processes, not specific to music (e.g. 
memories). However, as mechanisms are here studied in the context of music as the means for self-regulation, they will be addressed as musical mechanisms.

\section{Research on strategies and mechanisms in the context of musical affect regulation}

The study of strategies within musical affect regulation is especially challenging due to the unfitness of general affect regulation models to the case of music (Randall, Rickard, \& Vella-Brodrick, 2014) and the difficulty in defining strategies and differentiating them from other concepts such as musical goals and tactics (Baltazar \& Saarikallio, 2016). Studies differ in whether the strategy as a concept refers to processes identified in general affect regulation or processes encountered specifically in music, but overall, music has been reported to facilitate strategies such as reappraisal (Chin \& Rickard, 2014a; Randall et al., 2014), entertainment/fun seeking (Gebhardt, Kunkel, \& Von Georgi, 2014; Saarikallio \& Erkkilä, 2007), relaxation (Van Goethem \& Sloboda, 2011), revving up/energizing (DeNora, 1999; Saarikallio, 2011), and finding solace (Saarikallio \& Erkkilä, 2007) (see a complete compilation in Baltazar \& Saarikallio, 2016). Recent work has also noted that different strategies have differing impacts on development, wellbeing, and psychological health 
(Carlson et al., 2015; Chin \& Rickard, 2014a; Gebhardt et al., 2014; Marik \& Stegemann, 2016; Schäfer \& Sedlmeier, 2009; Thoma, Ryf, Mohiyeddini, Ehlert, \& Nater, 2012; Thomson, Reece, \& Di Benedetto, 2014).

As for the underlying mechanisms in music, the first approach was taken towards musical emotion induction (Juslin, Barradas, \& Eerola, 2015; Juslin \& Västfjäll, 2008a, 2008b). Juslin and Västfjäll (2008a) identified six mechanisms underlying emotion induction through music: brain stem reflex, evaluative conditioning, emotional contagion, visual imagery, episodic memory, and musical expectancy. Later, rhythmical entrainment (2008b) and aesthetic judgment (Juslin, 2013) were added to the list.

However, there is more to affect regulation than emotion induction (for example, suppression of affective responses). Within affect regulation, Van Goethem and Sloboda (2011) identified eight underlying mechanisms: type of music, familiarity, unrelated activity, emotion of music, memories, content of music, related activities, and other world (from higher to lower frequency). Although not named as such, other musical mechanisms have been sparsely present in other studies, such as connection, memory triggers, high aesthetic value, and message (Van den Tol \& Edwards, 2013) and extramusical associations, acoustical properties, and identification with artist/lyrics (Bishop et al., 2007). 
While conceptually differentiated, strategies and mechanisms occur as interrelated elements of affect regulation. Yet, only preliminary studies of their interlinkage exist. Van Goethem and Sloboda (2011) reported an association between the strategy active coping and the mechanisms memories and related/unrelated activities, and between the strategy relaxation and emotion, type of music and familiarity. Saarikallio, Baltazar \& Västfjäll (2017) reported that strategies distraction and emotion induction were linked to musical mechanisms, while strategy processing was linked to both musical and mental mechanisms.

\section{Aim of the current study}

Despite the advancements of studying music-related regulation strategies and mechanisms, there still is great conceptual ambivalence in the field (Baltazar \& Saarikallio, 2016). In particular, it is far from clear how each mechanism is used in cooperation with a particular regulation strategy. For this reason, the principal aim of the present study was to explore the associations between strategies and mechanisms used while regulating affect through music. 


\section{Methods}

Participants

The sample consisted of 571 participants, of which 24 were excluded due to incomplete answers, leading to a final sample of 547 participants. The sample's characteristics are described in Table 1. The participants were recruited through several means: schools, mailing lists, social media, webpages for recruiting participants, psychology experiments webpages, and the researchers' personal networks (there is no data on how many participants came from each). Except for the participants who were recruited directly from schools, the participation was done online. All the participants were voluntary and gave their informed consent. No compensation was offered.

Table 1. Descriptive statistics of the sample.

$\mathrm{N}=547$ participants

\begin{tabular}{|c|c|c|c|c|c|c|c|}
\hline & & $n(\%)$ & $M$ & $S D$ & Median & Min. & Max. \\
\hline \multirow[t]{4}{*}{ Age } & & & 21 & 4,72 & 20 & 13 & 30 \\
\hline & $13-15$ & 63 & & & & & \\
\hline & $16-18$ & $(12 \%)$ & & & & & \\
\hline & $19-21$ & 135 & & & & & \\
\hline \multirow[t]{2}{*}{ Gender } & Female & 249 & & & & & \\
\hline & Male & 289 & & & & & \\
\hline
\end{tabular}




\begin{tabular}{lll} 
& Other & 9 \\
\hline Nationality & Finnish & 192 \\
& Portuguese & 195 \\
& American & 67 \\
& Other (less & 93 \\
& than 15 counts) & $(17 \%)$ \\
\hline Occupation & Elementary student & 38 \\
& Secondary student & 146 \\
& Bachelor student & 150 \\
& Master student & 57 \\
& Doctoral student & 28 \\
& Working & 92 \\
& Homemaker & 3 \\
& Unemployed & 33 \\
\hline Music & None & 146 \\
& Subject at school & 310 \\
education & Extracurricular & 130 \\
& Private tutoring & 170 \\
& Self-taught & 137 \\
& Music academy & 61 \\
& Music conservatory & 31 \\
& University & 13 \\
\hline
\end{tabular}

Note. Totals may not round up to $100 \%$ due to rounding. Min. $=$ Minimum value; Max. = Maximum value 


\section{Measures - Questionnaire}

The data were collected through a computer-based questionnaire, designed specifically for this study. The participants were asked to recall the last moment when they engaged with music (by listening, playing, watching concerts, or creating) with some affective intention/outcome. Participants then identified which strategies they put in practice and which mechanisms were the most relevant. The strategies and mechanisms presented as options were retrieved from the literature (Baltazar \& Saarikallio, 2016) and consisted of 13 mechanisms and 25 strategies (organized in five categories). While the minimum was to choose one strategy and one mechanism, participants could choose as many options as they wished. The questionnaire is in Appendix.

\section{Statistical procedures}

Categorization As a standard first step for dimensionality reduction methods, a preliminary analysis was conducted to assess the structure of the answers, perform some necessary categorization, and label categories. Categorization, and sometimes recoding, of data might be necessary for correspondence analysis (Greenacre, 1984; Kaciak \& Louviere, 1990), given that this tecnique is 
based on a table of crossed frequencies (i.e. contingency table). For the variable Mechanisms, no further categorization was needed. The participants were allowed to choose more than one mechanism and order them from the most to the least relevant. However, only the first choice is included in this analysis. In the particular case of the mechanism musical expectancy, only 8 participants selected this mechanism as a first choice. Given the small frequency, musical expectancy was replaced by the participants' second mechanism. See Table 2 for the list of mechanisms and their definitions. 


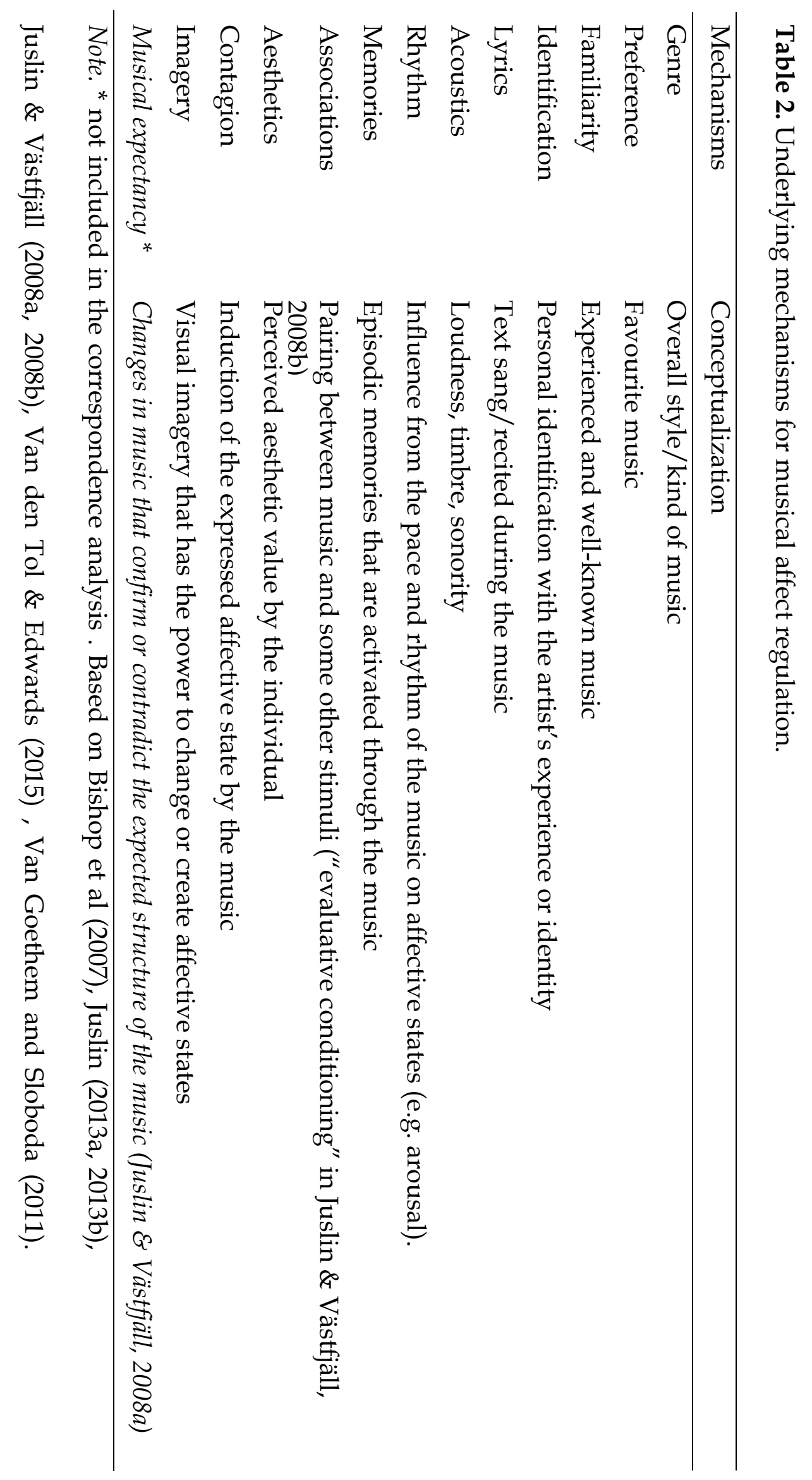


As for Strategies, the participants could choose from one up to five categories, thus creating multi-answer data. The five main categories already present in the questionnaire were kept: 1 - Focus on thoughts, affective state and/or situation, 2 - Distraction from thoughts, affective state and/or situation, 3 - Cognitive Work, 4- Modify feelings, 5- Bodily reactions/behaviour. A total of 335 participants chose just one of these options. For the 128 participants who identified two strategies, it was necessary to create new categories based on combinations in order to represent the simultaneous use of strategies. As the combination of Body reactions/behaviour with other strategy was rare (17 occurrences), these participants were categorized on the main category "Body". Eighty-four participants chose three or more strategies, and a specific category reflecting the simultaneous (and possibly low differentiated) strategies was created for them (Three or more). As the count for each possible combination of three strategies was low, it would not be feasible to keep them separately. Table 3 shows the final strategy categories and presents their code names that will be used in the text from now on. The specific strategies included in each category can be seen in the questionnaire (Appendix). Overall, the categorization procedure resulted in a total of 12 mechanisms and 12 strategies to be used in the subsequent analyses. 
Table 3. Strategies and their categorization.

\begin{tabular}{ll} 
Categories & Code name \\
\hline Focus on thoughts, feelings, and/or situation & Focus \\
Distract from thoughts, feelings, and/or situation & Distract \\
Cognitive work & Cognitive work \\
Modify feelings/experience & Modify feelings \\
Bodily reactions and behaviour & Bodily reactions \\
Focus and distract & FD \\
Focus and cognitive work & FC \\
Focus and modify & FM \\
Distract and cognitive work & DC \\
Distract and modify & DM \\
Cognitive work and modify & CM \\
Three or more & +3
\end{tabular}

Note. The combined categories included all the strategies belonging to the individual categories. The three or more category includes all the combinations with three or more strategies.

Correspondence analysis Correspondence analysis (CA) is a descriptive and exploratory technique developed to deal with contingency tables (Benzécri, 1992). Described as a "variant of principal component analysis (PCA) applicable to categorical data" (Greenacre, 2015, p. 1), this technique is especially useful when the size of the tables does not allow to see appropriately the underlying associations. Complex data is simplified by the extraction of the least number of dimensions that explain the most inertia (i.e. variance). Besides demonstrating 
the association between variables, CA projects these associations into a biplot, with the distances between the points calculated through the chi-square statistic.

This technique perfectly fits to the current data, as it was categorical, included several levels, its complexity did not allow to directly perceive underlying associations, and there was no model to explain/predict it (Greenacre, 1984). Because our aim was to describe both variables (Strategies and Mechanisms) and explore the associations between them, we computed symmetrical coordinates. The analyses were computed with the Matlab package Correspondence Analysis with Rotations (CAR; Lorenzo-Seva, van de Velden, \& Kiers, 2009).

\section{Results}

Extracting the dimensions and their contributing variables

The first step in CA is the extraction of the dimensions explaining the most of the inertia (i.e. variance) by analyzing the cross-tabulated data. The chi-square test of independence examined the relation between the row and column variables in the contingency table (mechanisms and strategies; see Table 4) and showed that the relation was significant, $X^{2}(121, N=547)=147.24, p<.05$. Power-divergence statistic with lambda $=2 / 3($ Read and Cressie, 1998) was used as suggested for small tables (Parshall, Kromrey, \& Dailey, 1995). The first 
three dimensions explained $78.5 \%$ of the inertia, with each one explaining more than the expected average $(33.4 \%, 25.3 \%$, and $19.8 \%$, respectively). The analysis of the scree plot and eigenvalues (Table 5), and the Hull's parallel analysis (Lorenzo-Seva, 2011) confirmed the extraction of the three dimensions.

One of the outputs of $\mathrm{CA}$ is the contribution of each row and column to the dimensions. The rows and columns with higher contributions are the most meaningful for the dimension and relevant for its interpretation. The contributions that are larger than the average (i.e. $1 /$ number of rows and $1 /$ number of columns) are considered salient contributions and retained for interpretation. Table 6 shows the contributions for each row and column, with salient values (i.e. values higher than the average contribution, 0.083) in bold face. 
Table 4. Contingency table with Mechanisms as row and Strategies as column.

\begin{tabular}{clllllllllllll}
\hline & F & D & C & MF & B & FD & FC & FM & DC & D & MB & +3 & Total \\
\hline Ge & 8 & 15 & 3 & 4 & 3 & 1 & 2 & 0 & 0 & 0 & 0 & 3 & 39 \\
$\mathrm{Pr}$ & 6 & 11 & 6 & 7 & 5 & 4 & 1 & 2 & 2 & 4 & 0 & 9 & 57 \\
Fa & 7 & 7 & 3 & 2 & 0 & 0 & 1 & 0 & 0 & 2 & 0 & 4 & 26 \\
$\mathrm{Id}$ & 3 & 0 & 5 & 1 & 0 & 1 & 1 & 0 & 2 & 0 & 0 & 2 & 15 \\
$\mathrm{Ly}$ & 9 & 11 & 10 & 2 & 0 & 4 & 7 & 1 & 5 & 2 & 0 & 9 & 60 \\
$\mathrm{Ac}$ & 7 & 10 & 7 & 1 & 3 & 1 & 2 & 0 & 2 & 1 & 1 & 4 & 39 \\
$\mathrm{Rh}$ & 14 & 20 & 6 & 13 & 10 & 5 & 2 & 2 & 1 & 3 & 3 & 11 & 90 \\
$\mathrm{Me}$ & 8 & 6 & 6 & 6 & 3 & 1 & 6 & 2 & 2 & 4 & 3 & 10 & 57 \\
$\mathrm{As}$ & 3 & 3 & 6 & 3 & 2 & 1 & 2 & 0 & 1 & 1 & 1 & 4 & 27 \\
$\mathrm{Ae}$ & 8 & 8 & 4 & 6 & 3 & 1 & 5 & 4 & 1 & 7 & 0 & 15 & 62 \\
$\mathrm{Co}$ & 2 & 8 & 5 & 6 & 7 & 5 & 2 & 2 & 2 & 3 & 3 & 5 & 50 \\
$\mathrm{Im}$ & 3 & 2 & 5 & 3 & 0 & 0 & 1 & 0 & 1 & 1 & 1 & 8 & 25 \\
\hline Total & 78 & 101 & 66 & 54 & 36 & 24 & 32 & 13 & 19 & 28 & 12 & 84 & 547 \\
\hline
\end{tabular}

Note. Columns (Strategies): $\mathrm{F}=$ Focus, $\mathrm{D}=$ Distraction, $\mathrm{CW}=$ Cognitive work, $\mathrm{MF}=$ Modify feelings, $\mathrm{B}=$ Bodily reactions, $\mathrm{FD}=$ Focus and Distract, $\mathrm{FM}=$ Focus and Modify feelings, $\mathrm{DC}=$ Distract and cognitive work, $\mathrm{DM}=$ Distract and Modify,$+3=$ More than three strategies.

Rows (Mechanisms): Ge $=$ Genre, $\operatorname{Pr}=$ Preference, $\mathrm{Fa}=$ Familiarity, $\mathrm{Id}=$ Identification, $\mathrm{Ly}=$ Lyrics, $\mathrm{Ac}=$ Acoustics, $\mathrm{Rh}=$ Rhythm, $\mathrm{Me}=$ Memories, $\mathrm{As}=$ Associations, $\mathrm{Ae}=$ Aesthetics, $\mathrm{Co}=$ Contagion, Im = Imagery.

Table 5. Eigenvalues, percentage of inertia explained, and scree plot for the first five dimensions.

\begin{tabular}{lllll}
\hline Dim. & Eigenvalue & $\%$ & Cum $\%$ & Scree plot \\
\hline 1 & 0.0898 & 33.4 & 33.4 & $* * * * * * * * * * * * * * * * * * * * * * * * * * * * * * * * * * * * * * * *$ \\
2 & 0.0682 & 25.3 & 58.7 & $* * * * * * * * * * * * * * * * * * * * * * * * * * * * * *$ \\
3 & 0.0533 & 19.8 & 78.5 & $* * * * * * * * * * * * * * * * * * * * *$ \\
4 & 0.0252 & 9.4 & 87.9 & $* * * * * * * * * * * *$ \\
5 & 0.0163 & 6.1 & 94.0 & $* * * * * * * *$ \\
\hline
\end{tabular}

Note. Dim. - Dimensions; \% - Percentage of inertia explained by each dimension; Cum\% -

Cumulative percentage of inertia 
Table 6. Rotated symmetrical coordinates for each category under Strategies and Mechanisms and their respective contributions for each of the extracted dimensions (in percentage).

\begin{tabular}{|c|c|c|c|c|c|c|}
\hline \multirow{3}{*}{ Strategies (Columns) } & \multirow{2}{*}{\multicolumn{3}{|c|}{$\begin{array}{c}\text { Coordinates } \\
\text { Dimension }\end{array}$}} & \multirow{2}{*}{\multicolumn{3}{|c|}{$\begin{array}{c}\text { Contributions (in \%) } \\
\text { Dimension }\end{array}$}} \\
\hline & & & & & & \\
\hline & 1 & 2 & 3 & 1 & 2 & 3 \\
\hline Focus & 0.051 & 0.323 & 0.536 & 0.1 & 5.7 & 16.3 \\
\hline Distract & 0.438 & 0.657 & 0.207 & 12. & 30.5 & 3.1 \\
\hline Cognitive work & -0.870 & 0.157 & 0.033 & 32. & 1.1 & 0.1 \\
\hline Modify & 0.404 & -0.151 & -0.346 & 5.7 & 0.9 & 4.7 \\
\hline Body & 0.617 & 0.244 & -1.041 & 8.9 & 1.5 & 28.4 \\
\hline FD & -0.260 & 0.272 & -1.029 & 1.1 & 1.2 & 18.5 \\
\hline FT & -0.510 & -0.363 & 0.400 & 5.4 & 2.9 & 3.7 \\
\hline FM & 0.634 & -1.300 & -0.324 & 3.4 & 15.4 & 1.0 \\
\hline DT & -1.479 & 0.019 & -0.229 & 26. & 0.0 & 0.7 \\
\hline $\mathrm{DM}$ & 0.413 & -1.004 & 0.156 & 3.1 & 19.7 & 0.5 \\
\hline $\mathrm{TM}$ & -0.088 & -0.281 & -1.404 & 0.1 & 0.7 & 17.2 \\
\hline+3 & -0.034 & -0.588 & 0.289 & 0.1 & 20.3 & 5.1 \\
\hline \multicolumn{7}{|l|}{ Mechanisms (Rows) } \\
\hline Genre & 0.585 & 1.030 & 0.427 & 8.6 & 28.9 & 5.2 \\
\hline Preference & 0.226 & -0.068 & -0.223 & 1.9 & 0.2 & 2.1 \\
\hline Familiarity & 0.334 & 0.313 & 1.032 & 1.9 & 1.8 & 20.2 \\
\hline Identification & -1.804 & 0.181 & 0.042 & 31. & 0.3 & 0.0 \\
\hline Lyrics & -0.768 & 0.125 & 0.371 & 22. & 0.7 & 6.0 \\
\hline Acoustics & -0.302 & 0.647 & 0.145 & 2.3 & 11.4 & 0.6 \\
\hline Rhythm & 0.497 & 0.269 & -0.342 & 14. & 4.6 & 7.7 \\
\hline Memories & -0.094 & -0.527 & 0.001 & 0.3 & 11.1 & 0.0 \\
\hline Association & -0.536 & 0.006 & -0.245 & 5.0 & 0.0 & 1.2 \\
\hline Aesthetics & 0.388 & -0.904 & 0.423 & 6.0 & 35.5 & 8.1 \\
\hline Contagion & 0.091 & -0.088 & -1.129 & 0.3 & 0.3 & 46.4 \\
\hline Imagery & -0.519 & -0.548 & 0.330 & 4.4 & 5.2 & 2.0 \\
\hline
\end{tabular}

Note. The values with a contribution higher than average are in bold face. 
The values in Table 6 are further represented in a visual translation in Figures 2(a), 2(b), and 2(c). As more than two dimensions were extracted and the dimensions were not correlated, the solution was orthogonally rotated (varimax) to improve its graphical representation (Lorenzo-Seva et al., 2009; Van De Velden \& Kiers, 2005). No weighting system was applied, as it yielded the best results in Bentler's simplicity index (1997) (before rotation: .587 and .480 , after rotation: .935 and .935 , for row and column coordinates respectively).

Figure 2(a) depicts all the strategy and mechanism categories projected simultaneously in the space created by the associations between them, in dimensions 1 and 2. Figure 2(b) includes dimension 1 and 3, while Figure 2(c) represents the dimensions 2 and 3. The variables that have a stronger contribution for the dimension are closer to each extreme; the central position shows a contribution close to zero. The categories retained for interpretation, due to their significant contributions, are circled in the biplots. Two strategies (modify feelings, cognitive work and focus) and three mechanisms (preference, association, and imagery) did not have salient contributions for any of the dimensions. 


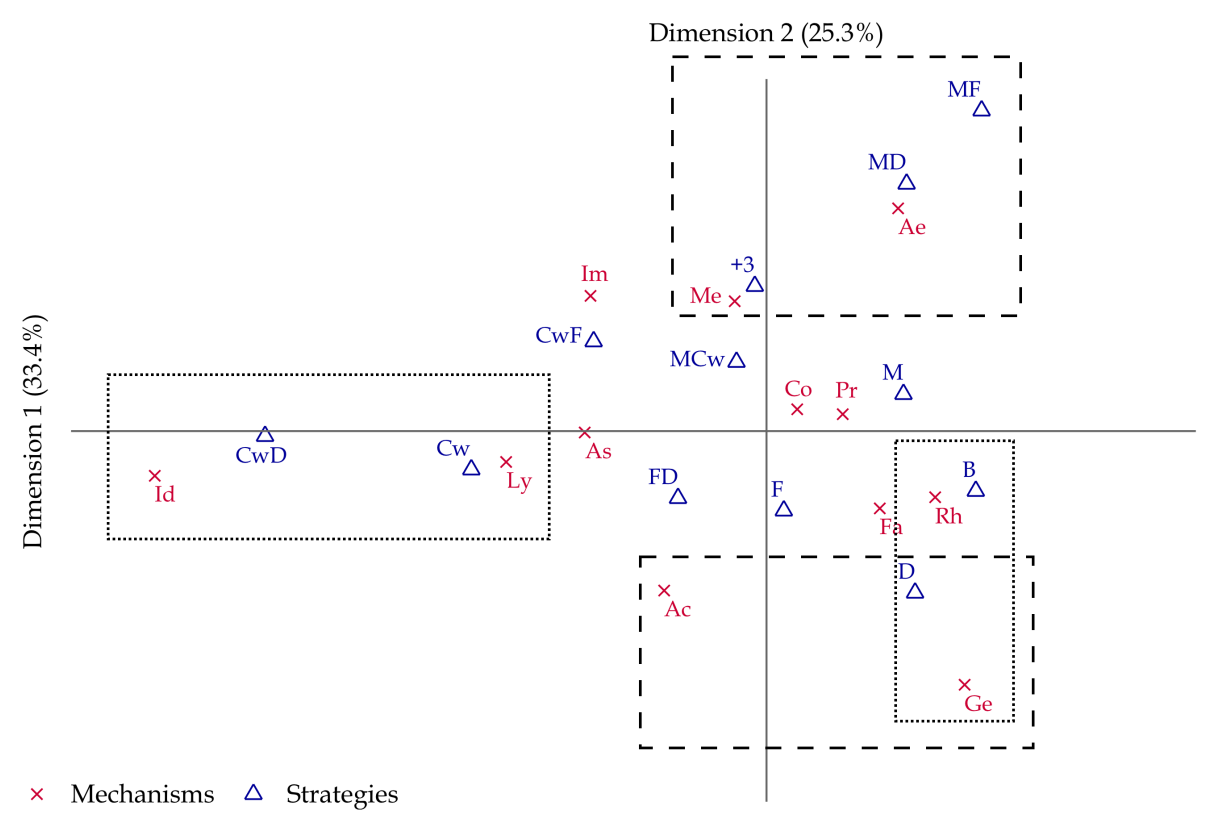

Figure 2(a). Biplot with visual representation of dimensions 1 and 2 . The categories with significant contributions to dimension 1 are inside the dotted line and to dimension 2 are inside the dashed line. 


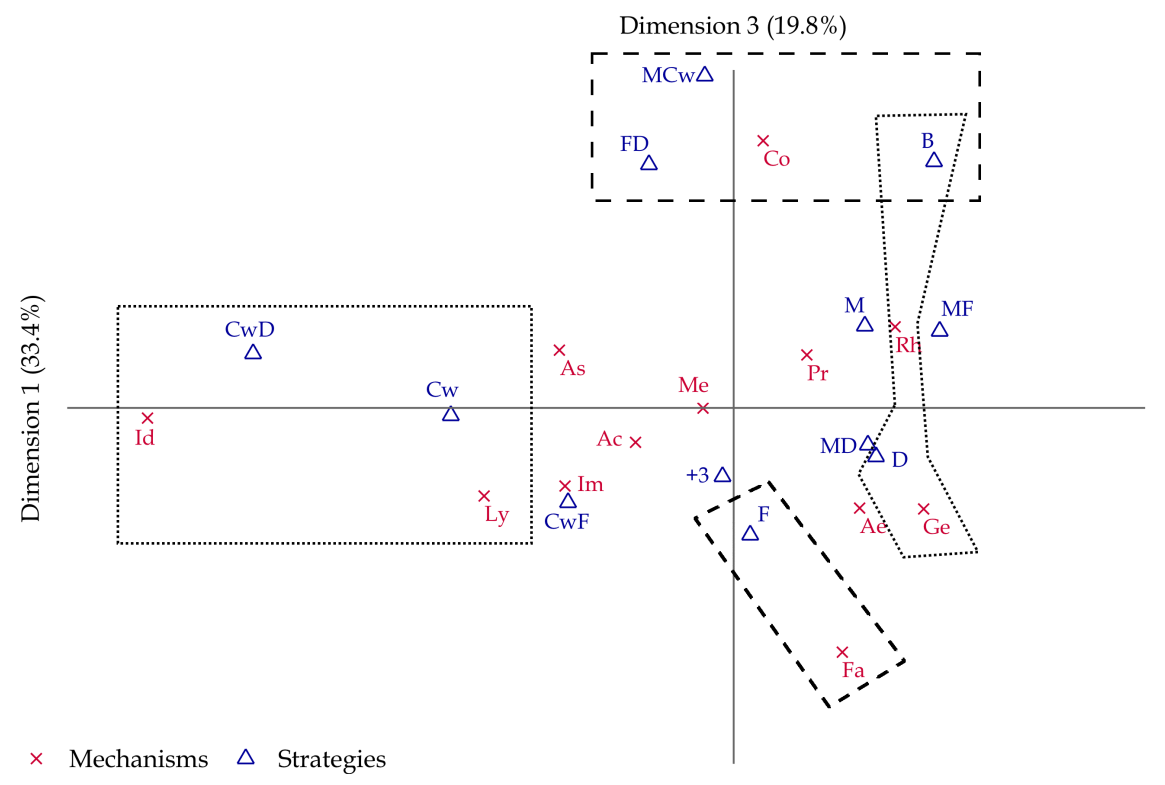

Figure 2(b). Biplot with visual representation of dimension 1 and 3 . The categories with significative contributions to dimension 1 are inside the dotted line and to dimension 3 are inside the dashed line. 


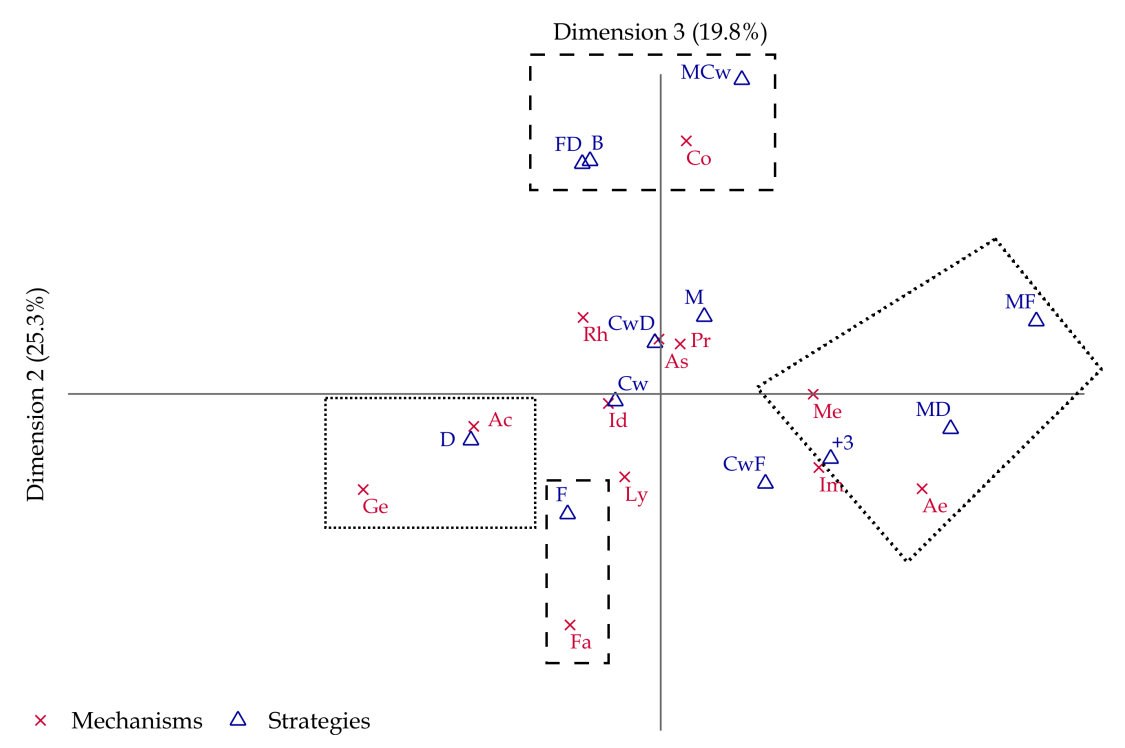

Figure 2(c). Biplot with visual representation of dimension 2 and 3 . The categories with significative contributions to dimension 2 are inside the dotted line and to dimension 3 are inside the dashed line.

Describing the extracted dimensions

The analysis resulted in a three-dimensional solution built of both regulatory strategies and mechanisms. The description of the dimensions is based on the analysis of the relevant strategies and their associations with musical mechanisms. Table 7 summarizes the features of each dimension that will be later used for their interpretation. 
Table 7. The three dimensions extracted, their contributions, and labelling.

\begin{tabular}{|c|c|c|c|c|}
\hline $\mathrm{D}$ & $\begin{array}{l}\text { Explained } \\
\text { inertia }\end{array}$ & $\begin{array}{l}\text { Strategies and } \\
\text { mechanisms }\end{array}$ & Poles' labelling & $\begin{array}{l}\text { Underlying } \\
\text { component }\end{array}$ \\
\hline \multirow[t]{2}{*}{1} & $33.4 \%$ & $\begin{array}{l}\text { Cognitive work } \\
\text { Cognitive work and } \\
\text { distract } \\
\text { Identification } \\
\text { Lyrics }\end{array}$ & Cognitive work & \multirow{2}{*}{ Cognition } \\
\hline & & $\begin{array}{l}\text { Distract } \\
\text { Body } \\
\text { Rhythm } \\
\text { Genre }\end{array}$ & Entertainment & \\
\hline \multirow[t]{2}{*}{2} & $25.3 \%$ & $\begin{array}{l}\text { Three or more } \\
\text { Modify and distract } \\
\text { Modify and focus } \\
\text { Aesthetics } \\
\text { Memories }\end{array}$ & Affective work & \multirow[t]{2}{*}{ Feelings } \\
\hline & & $\begin{array}{l}\text { Distract } \\
\text { Genre } \\
\text { Acoustics }\end{array}$ & Distraction & \\
\hline \multirow[t]{2}{*}{3} & $19.8 \%$ & $\begin{array}{l}\text { Body } \\
\text { Focus and distract } \\
\text { Modify and think } \\
\text { Contagion }\end{array}$ & Revival & \multirow[t]{2}{*}{ Body } \\
\hline & & $\begin{array}{l}\text { Focus } \\
\text { Familiarity }\end{array}$ & Focus situation & \\
\hline
\end{tabular}

Notes: $\mathrm{D}=$ Dimensions. The mechanisms were italicized in order to facilitate the reading through the table.

By taking into account both poles of the three dimensional solution (Table 7), the results reveal six major groups of strategy-mechanism combinations, which portray different processes of affect regulation through music. The labelling of the dimensions (columns 4 and 5 in Table 7) was done 
by analyzing and counterposing the strategies and mechanisms on the poles (column 3). We suggest looking at each dimension as representing a higher or lowers focus on a component of affect regulation: cognition, feelings, bodily reactions. The visual representation of these three dimensions can be seen in Figure 3.

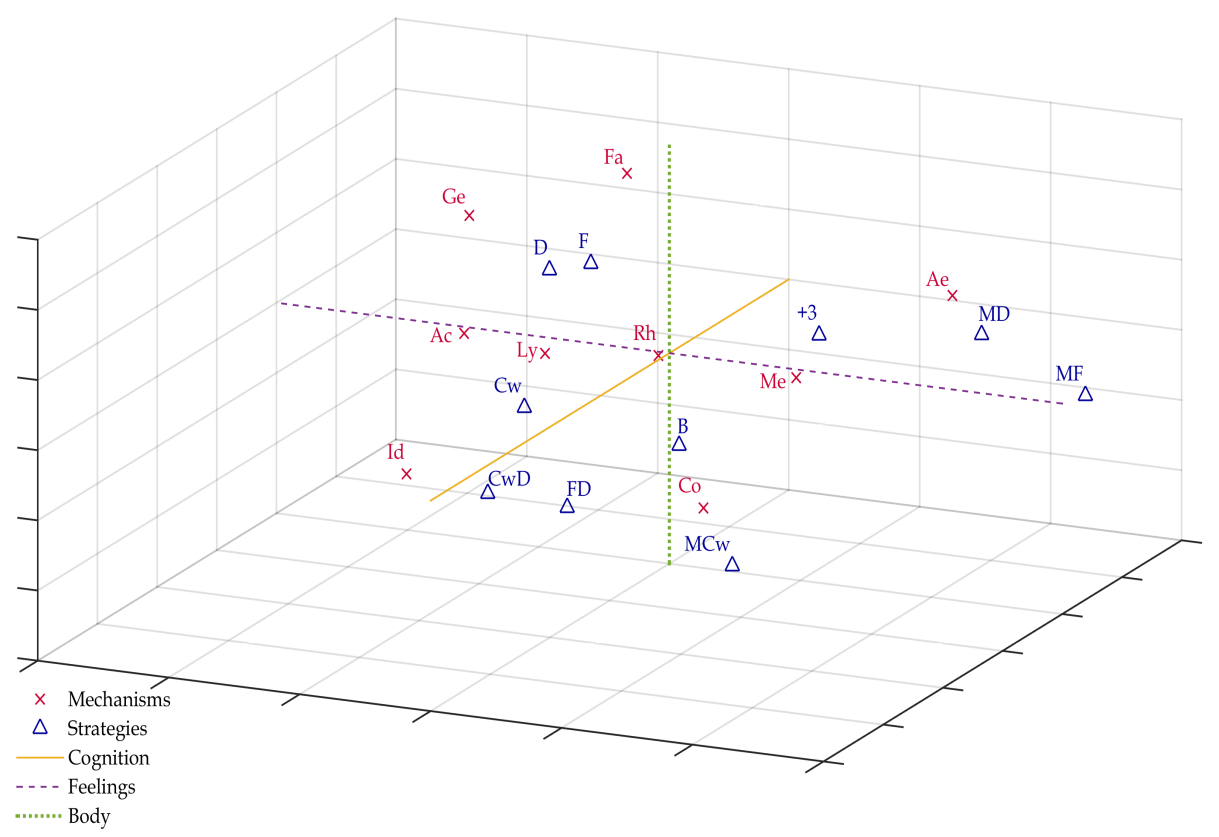

Figure 3. Three-dimensional projection of the associations between strategies and mechanisms that had relevant contributions to the axes (dimensions Cognition, Feelings, and Body). 


\section{Discussion}

The three-dimensional solution emerging from the data describes musical affect self-regulation as a combination of strategies and mechanisms across three affective components: cognition, feelings, and bodily reactions. The solution serves as a base for a model of strategic use of music for affect self-regulation (Figure 4).

The model of strategic use of music for affect self-regulation In the following paragraphs, we will discuss this emergent model and its constituent elements by starting with the extracted dimensions (representing the three core affective components) and their respective poles, continuing with the division of strategies and mechanisms into two groups, illustrated by the two halves of Figure 4.

Dimension 1: Cognition (cognitive work vs entertainment)

Dimension 1 shows how close or distant the regulation was to cognition. One pole represents cognitive work, which constitutes a separate major group of regulation strategies (Garnefski, Kraaij, \& Spinhoven, 2001), and includes, for example, reappraisal and perspective taking. Reappraisal specifically has been linked to higher effectiveness and better affective outcomes, both in general regulation (Augustine \& Hemenover, 2009; Gross \& John, 2003) and musical 


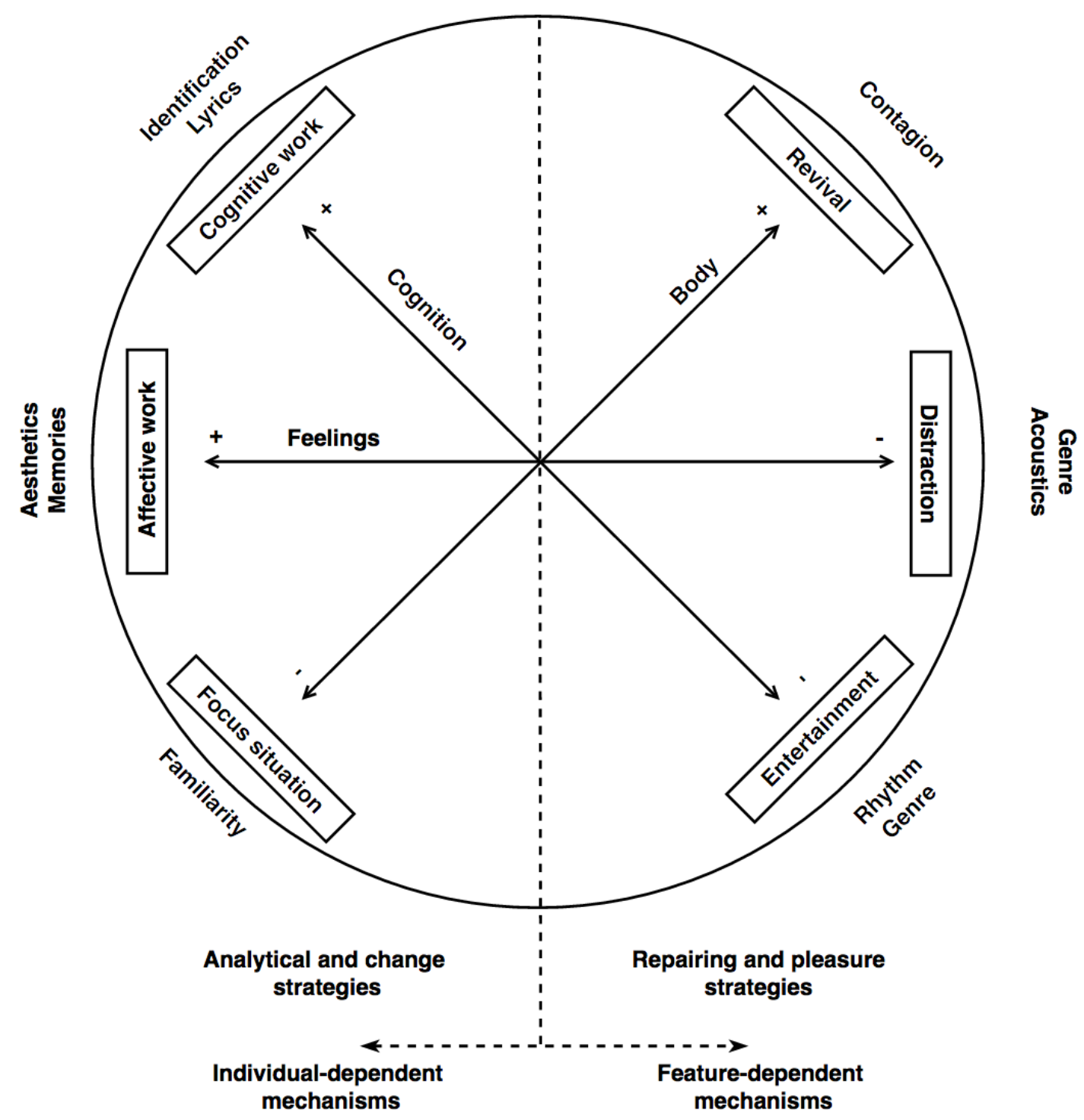

Figure 4. Model of strategic use of music for affect self-regulation.

Note. A higher use of the process that names the dimension (e.g. cognition) is marked with ' + ' and a lower use of that process if marked with ' - '. 
regulation (Chin \& Rickard, 2014b). Regulation through cognitive work can be seen as an effort of gaining new meanings before a total response takes place (antecedent-focused; Gross, 1998). The combined use of cognitive work and distraction might reveal the supporting effect of disengagement from undesired thoughts or feelings in attaining new cognitive perspectives. The mechanisms identification and lyrics point at a desirable congrutiy with the artists/emotional content and with the extracted meaning to support cognitive strategies.

As for the other pole of this dimension, distraction and body signal an attempt at turning to non-cognitive stimuli for influencing mood and arousal. This has been identified by Saarikallio and Erkkilä (2007) as entertainment, a strategy of having music in the background for lifting up spirits and maintaining positive mood. Similarly, the model of activation and arousal modulation with music (Gebhardt \& Von Georgi, 2007), includes fun stimulation as a basic dimension. The regulation of bodily feelings got a less relevant score in this dimension and it possibly assists entertainment through relaxation or energizing. The disengagement from cognitive processing seems to be facilitated by music features like rhythm and genre. Music's styles and features have already been reported to serve different affective goals (Hakanen, 1995). One particular way of taking advantage of genre and beat is through ironicallyenjoyed music, which might be more stimulating than preferred music (van den Tol \& Giner-Sorolla, 2016). 
Dimension 2: Feelings (affective work vs distraction)

The second dimension indicates whether regulation particularly focuses on feelings and affective reactions (labelled affective work) or aims to disengage from them (labelled distraction). Affective work involves a large variety of strategies and is highly complex: the variables more than 3 strategies, modify and distract, modify and focus, all contributed significantly to this pole. It encompasses, amongst others, three strategies from Saarikallio and Ekkilä's model (2007): happy mood maintenance, solace and strong sensations, which have in common the use of affective resources, either by preserving experienced states, changing them, or creating new ones. Regarding mechanisms, this pole was linked to enjoyment of beauty (aesthetics). Interestingly, Saarikallio, Nieminen, and Brattico (2013) report that people who relate more to aesthetic components of music tend to use it to elicite strong affective responses. Moreover, aesthetic fruition may be used to mood enhacement (Van den Tol \& Edwards, 2015). The second supporting mechanism revealed to be memories. In the context of sad music listening, memories related to feeling closer to others and intensifying sadness (Van den Tol \& Edwards, 2015), which are processes close to affective work.

The opposite pole of this dimension represents distraction, which is one of the most common strategies used while listening to music (Boer \& Fischer, 
2012; Van Goethem \& Sloboda, 2011). Distraction provides the possibility of shifting from negative stimuli to positive or neutral music, thus avoiding the undesired affective states (Gross, 2015). Recent literature suggests that distraction might be an adaptive strategy due to its low engagement in negative thoughts/feelings (Carlson et al., 2015; Van den Tol \& Edwards, 2015). Distraction has some similarities with entertainment both at strategic and musical level: withdraw from cognitive/affective processing and use of music's features to either distract or have fun.

\section{Dimension 3: Body (revival vs focus on situation)}

In the third dimension, we found a differentiation between the focus on arousal states and on the experienced situation or task at hand. The first pole is linked to modifying bodily feelings through relaxing, energizing, and improving flow (here named as revival). Music has been often identified as a means of relaxation (DeNora, 1999; Saarikallio et al., 2017) and energizing (Bishop et al., 2007). Contagion was the supporting mechanism for revival. This mechanism has the ability of inducing the music's expressed valence and arousal, and it has been found to successfully contribute to relaxation (Saarikallio et al., 2017; Van Goethem \& Sloboda, 2011).

The opposing pole does not show focus on bodily change. Instead, the attention is set in the situation and focus is tuned on to the experience and 
related thoughts, feelings, or surroundings (here named as focus on situation). It might be an attempt at getting a better feel of what is happening or concentrating on some specific task (e.g. studying). Music can indeed be used to improve mental and physical performance (Bishop et al., 2007; Laukka \& Quick, 2013). In terms of mechanisms, focus on situation was related to familiarity of music. Interestingly, it has been observed that familiar music has a more positive effect on word memory tasks than unfamiliar music (Chew, Yu, Chua, \& Gan, 2016). One might hypothesize that familiar music leaves more cognitive and affective resources available for focusing on the phenomenon while, simultaneously, providing stability to the individual.

\section{Regulation strategies: emerging patterns}

On the left side of the model (Figure 4), we have strategies related to a higher mental processing, either by cognitive work, affective work, or deployment of attention to the current situation. Opposed to these, on the right side, we can find strategies concerning the regulation of arousal levels (revival), distraction, and entertainment. There is, thus, a contrast between active, contemplating, affect-processing and cognition-loaded regulation (through what we called analytical and change strategies) and more passive, pleasure-oriented, and bodyfocused regulation (through what we called repairing and pleasure strategies) 
Furthermore, it was observed that the simultaneous use of strategies is frequent. This study grasped what Gross (2015) calls "blended" forms of regulation, in contrast with "pure" forms of regulation (i.e. involving only one strategy), which constitute the object of the vast majority of the empirical literature. Our results point to the importance of allowing multiple answers in order to explore different layers of regulation and simultaneous processes.

\section{Musical mechanisms: emerging patterns}

On the left side of the model (Figure 4), associated with analytical and change-oriented strategies, we find mechanisms that can be labelled individualdependent. Individual-dependent mechanisms are reflective of the experience emerging from the relationship between the individual and the music. This group included the following categories: identification, lyrics, aesthetics, memories, and familiarity.

Meanwhile, on the right side, supporting repairing and pleasureoriented strategies, situate the feature-dependent mechanisms. The featuredependent mechanisms are related to more universal characteristics of music regarding sound, style, and valence. This group was composed of the following mechanism categories: rhythm, genre, acoustics, and contagion.

We concluded, thus, that mechanisms are a bi-dimensional (individualand feature-dependent) variable and that these two categories have a particular 
interplay with the two major categories of regulation strategies (as seen in Figure 4). The categorization is somewhat in line with Sloboda and Juslin's (2001) coding of underlying emotions in music: iconic, intrinsic, and associative, with iconic and intrinsic coding reflecting feature-dependent and associative coding reflecting individual-dependent mechanisms. Likewise, in the context of adolescents' musical relaxation, Saarikallio, Baltazar, and Västfjäll (2017) grouped mechanisms into musical (including melody and music's valence/arousal, comparable to feature-dependancy) and mental (including memories and images, comparable to individual-dependancy).

\section{Conclusion}

The current study provided grounds for a clarified conceptual understanding of how the affect-regulatory processes structurally interrelate in a musical context. The emergent model portrays the existent links between two of the key elements of musical affect regulation: strategies and mechanisms. Besides the three-dimensional structure that emerged, the conceptual understanding gained from the model concerns the structure of mechanisms (bidimensional: feature- and individual- related) and strategies (bidimensional: analytical, focused on change and repairing, focused on pleasure), and the associations between the two variables (feature-related mechanisms associate with repairing strategies, and individual-related mechanisms associate with 
analytical strategies). Future research will be helpful to further explore the eventual relations between the three dimensions, individual factors, and wellbeing variables. 


\section{References}

Augustine, A. a., \& Hemenover, S. H. (2009). On the relative effectiveness of affect regulation strategies: A meta-analysis. Cognition \& Emotion, 23(6), 11811220. http://doi.org/10.1080/02699930802396556

Baltazar, M., \& Saarikallio, S. (2016). Toward a better understanding and conceptualization of affect self-regulation through music: A critical, integrative literature review. Psychology of Music, 44(6), 1500-1521. http://doi.org/10.1177/0305735616663313

Benzécri, J.-P. (1992). Correspondence analysis handbook. New York: Marcel Dekker.

Bishop, D. T., Karageorghis, C. I., \& Loizou, G. (2007). A grounded theory of young tennis players' use of music to manipulate emotional state. Journal of Sport \& Exercise Psychology, 29(5), 584-607.

Boer, D., \& Fischer, R. (2012). Towards a holistic model of functions of music listening across cultures: A culturally decentred qualitative approach. Psychology of Music, 40(2), 179-200. http://doi.org/10.1177/0305735610381885

Carlson, E., Saarikallio, S., Toiviainen, P., Bogert, B., Kliuchko, M., \& Brattico, E. (2015). Maladaptive and adaptive emotion regulation through music: a behavioral and neuroimaging study of males and females. Frontiers in Human Neuroscience, 9(August), 1-13. http://doi.org/10.3389/fnhum.2015.00466

Chew, A. S.-Q., Yu, Y.-T., Chua, S.-W., \& Gan, S. K.-E. (2016). The effects of familiarity and language of background music on working memory and language tasks in Singapore. Psychology of Music, 1-8. http://doi.org/10.1177/0305735616636209

Chin, T., \& Rickard, N. S. (2014a). Beyond positive and negative trait affect: Flourishing through music engagement. Psychology of Well-Being: Theory, Research and Practice, 4(25), 1-13. http://doi.org/10.1186/s13612-0140025-4

Chin, T., \& Rickard, N. S. (2014b). Emotion regulation strategy mediates both positive and negative relationships between music uses and well-being. Psychology of Music, 42(5), 692-713. http://doi.org/10.1177/0305735613489916

DeNora, T. (1999). Music as a technology of the self. Poetics, 27(1), 31-56. http://doi.org/10.1016/S0304-422X(99)00017-0

Ferguson, M. J., Hassin, R., \& Bargh, J. A. (2008). Implicit motivation: Past, present, and future. In J. Y. . Shah \& W. L. Gardner (Eds.), Handbook of motivation science (pp. 150-166). New York, NY: The Guildford Press.

Fleckenstein, K. S. (1991). Defining Affect in Relation to Cognition: A Response to Susan McLeod. Journal of Advanced Composition, 11(2), 447-453. http://doi.org/10.2307/20865808 
Garnefski, N., Kraaij, V., \& Spinhoven, P. (2001). Negative life events, cognitive emotion regulation and emotional problems. Personality and Individual Differences, 30(8), 1311-1327. http://doi.org/10.1016/S01918869(00)00113-6

Gebhardt, S., Kunkel, M., \& Von Georgi, R. (2014). Emotion modulation in psychiatric patients through music. Music Perception, 31(5), 485-493. http://doi.org/10.1525/MP.2014.31.5.485

Gebhardt, S., \& Von Georgi, R. (2007). Music, mental disorder and emotional reception behavior. Music Therapy Today, 8(3), 419-445.

Greenacre, M. (1984). Theory and applications to correspondence analysis. Orlando, Florida: Academic Press.

Greenacre, M. (2015). Correspondence analysis. In International Encyclopedia of the Social \& Behavioral Sciences (Second, pp. 1-5). Elsevier. http://doi.org/10.1016/B978-0-08-097086-8.42005-2

Groarke, J. M., \& Hogan, M. J. (2015). Enhancing wellbeing: An emerging model of the adaptive functions of music listening. Psychology of Music, 1-23. http://doi.org/10.1177/0305735615591844

Gross, J. J. (1998). Antecedent- and response-focused emotion regulation: divergent consequences for experience, expression, and physiology. Journal of Personality and Social Psychology, 74(1), 224-37.

Gross, J. J. (2015). Emotion Regulation : Current status and future prospects. Psychological Inquiry, 26, 1-26. http://doi.org/10.1080/1047840X.2014.940781

Gross, J. J., \& John, O. P. (2003). Individual differences in two emotion regulation processes: Implications for affect, relationships, and well-being. Journal of Personality and Social Psychology, 85(2), 348-362. http://doi.org/10.1037/0022-3514.85.2.348

Gross, J. J., \& Thompson, R. A. (2007). Emotion regulation: Conceptual foundations. In J. J. Gross (Ed.), Handbook of emotion regulation (pp. 3-26). New York, NY: The Guilford Press.

Hakanen, E. A. (1995). Emotional use of music by African American adolescents. Howard Journal of Communications., 5(3), 214-222. http://doi.org/10.1080/10646179509361664

Harmon-Jones, E., \& Harmon-Jones, C. (2015). Neural foundations of motivational orientations. In G. H. E. Gendolla, M. Tops, \& S. L. Sanders (Eds.), Handbook of biobehavioral approaches to self-regulation (pp. 175-187). New York, NY: Springer.

Juslin, P. N. (2013). From everyday emotions to aesthetic emotions: Towards a unified theory of musical emotions. Physics of Life Reviews, 10(3), 235-266. http://doi.org/10.1016/j.plrev.2013.05.008

Juslin, P. N., Barradas, G., \& Eerola, T. (2015). From sound to significance: Exploring the mechanisms underlying emotional reactions to music. The American 
Journal of Psychology, 128(3), 281-304.

http://doi.org/10.5406/amerjpsyc.128.3.0281

Juslin, P. N., \& Sloboda, J. A. (2010). Introduction: Aims, organization, and terminology. In N. Juslin, Patrik \& A. Sloboda John (Eds.), Handbook of music and emotion: Theory, research, applications (pp. 3-12). New York, NY: Oxford University Press.

Juslin, P. N., \& Västfjäll, D. (2008a). All emotions are not created equal: Reaching beyond the traditional disputes. The Behavioral and Brain Sciences, 31(5), 600-621. http://doi.org/10.1017/S0140525X08005554

Juslin, P. N., \& Västfjäll, D. (2008b). Emotional responses to music: The need to consider underlying mechanisms. The Behavioral and Brain Sciences, 31(5), 559-621. http://doi.org/10.1017/S0140525X08005293

Kaciak, E., \& Louviere, J. (1990). Multiple correspondence analysis of multiple choice experiment data. Journal of Marketing Research, 27(4), 455-465.

Koole, S. L. (2009). The psychology of emotion regulation: An integrative review. Cognition \& Emotion, 23(1), 4-41. http://doi.org/10.1080/02699930802619031

Krumhansl, C. L. (2002). Music: A link between cognition and emotion. Current Directions in Psychological Science, 11(2), 45-50. http://doi.org/10.1111/1467-8721.00165

Laukka, P., \& Quick, L. (2013). Emotional and motivational uses of music in sports and exercise: A questionnaire study among athletes. Psychology of Music, 41(2), 198-215. http://doi.org/10.1177/0305735611422507

Lorenzo-Seva, U. (2011). Horn's parallel analysis for selecting the number of dimensions in correspondence analysis. Methodology, 7(3), 96-102. http://doi.org/10.1027/1614-2241/a000027

Lorenzo-Seva, U., van de Velden, M., \& Kiers, H. a L. (2009). Oblique rotation in correspondence analysis: A step forward in the search for the simplest interpretation. The British Journal of Mathematical and Statistical Psychology, 62(Pt 3), 583-600. http://doi.org/10.1348/000711008X368295

Marik, M., \& Stegemann, T. (2016). Introducing a new model of emotion dysregulation with implications for everyday use of music and music therapy. Musicae Scientiae, 20(1), 53-67. http://doi.org/10.1177/1029864915622055

Parshall, C. G., Kromrey, J. D., \& Dailey, R. (1995). Comparison of Statistical Tests of Independence for Sparse I $x$ J Contingency Tables. San Francisco.

Randall, W. M., Rickard, N. S., \& Vella-Brodrick, D. A. (2014). Emotional outcomes of regulation strategies used during personal music listening: A mobile experience sampling study. Musicae Scientiae, 18(3), 275-291. http://doi.org/10.1177/1029864914536430

Saarikallio, S. (2011). Music as emotional self-regulation throughout adulthood. Psychology of Music, 39(3), 307-327. http://doi.org/http://dx.doi.org/10.1177/0305735610374894 
Saarikallio, S., Baltazar, M., \& Västfjäll, D. (2017). Adolescents' musical relaxation: understanding the related affective processing. Nordic Journal of Music Therapy. http://doi.org/10.1080/08098131.2016.1276097

Saarikallio, S., \& Erkkilä, J. (2007). The role of music in adolescents' mood regulation. Psychology of Music, 35(1), 88-109. http://doi.org/http://dx.doi.org/10.1177/0305735607068889

Saarikallio, S., Nieminen, S., \& Brattico, E. (2013). Affective reactions to musical stimuli reflect emotional use of music in everyday life. Musicae Scientiae, 17(1), 27-39. http://doi.org/10.1177/1029864912462381

Schäfer, T., \& Sedlmeier, P. (2009). From the functions of music to music preference. Psychology of Music, 37(3), 279-300. http://doi.org/10.1177/0305735608097247

Scherer, K. R. (2000). Psychological models of emotion. In J. Borod (Ed.), The Neuropsychology of Emotion (pp. 137-162). Oxford/New York: Oxford University Press.

Scherer, K. R. (2004). Which emotions can be induced by music? What are the underlying mechanisms? And how can we measure them? Journal of New Music Research, 33(3), 239-251. http://doi.org/10.1080/0929821042000317822

Scherer, K. R. (2005). What are emotions? And how can they be measured? Social Science Information, 44(4), 695-729. http://doi.org/10.1177/0539018405058216

Scherer, K. R., \& Peper, M. (2001). Psychological theories of emotion and neuropsychological research. Handbook of Neuropsychology 2nd Edition.

Sloboda, J. A., \& Juslin, P. N. (2001). Psychological perspectives on music and emotion. In J. A. Juslin, Patrik N., Sloboda (Ed.), Music and emotion: Theory and research (pp. 71-104). New York: Oxford University Press.

Sloboda, J. A., \& Juslin, P. N. (2010). At the interface between the inner and the outer world: Psychological perspectives. In P. N. . Juslin \& J. A. Sloboda (Eds.), Handbook of music and emotion: Theory, research, applications (pp. 73-97). New York: Oxford University Press.

Tahlier, M., Miron, A. M., \& Rauscher, F. H. (2013). Music choice as a sadness regulation strategy for resolved versus unresolved sad events. Psychology of Music, 41(6), 729-748. http://doi.org/10.1177/0305735612446537

Thoma, M. V., Ryf, S., Mohiyeddini, C., Ehlert, U., \& Nater, U. M. (2012). Emotion regulation through listening to music in everyday situations. Cognition \& Emotion, 26(3), 550-560. http://doi.org/10.1080/02699931.2011.595390

Thoma, M. V., Scholz, U., Ehlert, U., \& Nater, U. M. (2012). Listening to music and physiological and psychological functioning: The mediating role of emotion regulation and stress reactivity. Psychology \& Health, 27(2), 227-241. http://doi.org/10.1080/08870446.2011.575225

Thomson, C. J., Reece, J. E., \& Di Benedetto, M. (2014). The relationship between 
music-related mood regulation and psychopathology in young people. Musicae Scientiae, 18(2), 150-165. http://doi.org/10.1177/1029864914521422

Van De Velden, M., \& Kiers, H. A. L. (2005). Rotation in correspondence analysis. Journal of Classification, 22(2), 251-271. http://doi.org/10.1007/s00357-0050016-5

Van den Tol, A. J. M., \& Edwards, J. (2015). Listening to sad music in adverse situations: How music selection strategies relate to self-regulatory goals, listening effects, and mood enhancement. Psychology of Music, 43(4), 473-494. http://doi.org/10.1177/0305735613517410

van den Tol, A. J. M., \& Giner-Sorolla, R. (2016). Listening to ironically-enjoyed music: A self-regulatory perspective. Psychology of Music.

http://doi.org/10.1177/0305735616658956

Van Goethem, A. (2010). Affect regulation in everyday life: Strategies, tactics and the role of music (Unpublished doctoral dissertation). Keele University: UK.

Van Goethem, A., \& Sloboda, J. A. (2011). The functions of music for affect regulation. Musicae Scientiae, 15(2), 208-228. http://doi.org/10.1177/1029864911401174 


\section{APPENDIX}

Questionnaire

[section concerning the reported results]

How was music a 'tool' for you?

Music helped me to:

focus deeply on what was happening or what I was feeling.

Please specify on what:

experienced feelings

situation and/or its meaning and consequences

memories related to the situation or to the feelings

elements of the music that provided support and acceptance

distract myself.

Please specify from what:

thoughts

feelings

elements around me

memories

Please specify on what you focused:

visual and auditory imagery

aspects of music

pleasant thoughts and/or feelings

memoires

think about what happened or about what I was feeling.

Please specify how:

by having a rational view on it

by reflecting on it

by understanding it

by accepting it

change my way of thinking.

Please specify how:

by finding different meanings for the situation

by finding different meanings for the affective reaction

by seeing the situation/reaction through a distance

perspective

by suppressing my thoughts

manipulate my feelings.

Please specify how:

by seeking strong sensations

by maintaining or increasing what I was feeling

by decreasing or inhibiting what I was feeling

focus on my body and expressions.

Please specify how: 
performance)

by increasing body functioning (flow, endurance,

by revving up/energising

by meditating

by suprressing bodily reactions

by controlling my breathing and relaxing the muscles

by venting/discharging what I was feeling

by suppressing any expression of feelings

Which elements of music influenced you the most?

Select from the list and order them from the most important (on top) to the least important (bottom). The minimum selection is one; there is no maximum.

- the genre of music

- it was my preferred music

- it was some music that I already know quite well

- I could identify myself with the artist(s) during the song

- the lyrics

- acoustic features of the music (e.g. volume, timbre, sounds...)

- rhythm/ pace of the music

- memories linked to that music

- associations with other things outside the music

- I find that music very beautiful/ aesthetically valuable

- I started to feel the same emotions that were expressed by the music

- it provoked visual images in my mind

- it had changes during the song or developments that I could not predict 